\title{
ESTUDO DO COMPORTAMENTO DA COTA MÍNIMA DO RIO ACRE NOS ÚLTIMOS 43 ANOS E AS CONSEQUÊNCIAS PARA O ASSOREAMENTO FUTURO DO RIO
}

\author{
STUDY OF THE BEHAVIOR OF THE MINIMUM ACRE RIVER QUOTA IN THE LAST 43 \\ YEARS AND THE CONSEQUENCES FOR THE FUTURE RIVER FOSTERING
}

\section{Osmar José ACCORSI ${ }^{1}$, Esperidião Fecury Pinheiro de LIMA ${ }^{\mathbf{1}}$, Luciane Ferreira ALCOFORADO ${ }^{2}$, Orlando Celso LONGO²}

(1) Centro de Ciências Exatas e Tecnológicas CCET-UFAC. Campus Universitário - BR 364, Km 04 - Distrito Industrial - CEP: 69.920-900 Rio Branco - Acre. Endereços eletrônicos: ojaccorsi@gmail.com; pirifecury@uol.com.br (2) Programa de Pós-graduação em Engenharia Civil - UFF. Rua Passo da Pátria, 156 - $3^{\circ}$ andar - Sala 365 - Bloco "D"

- São Domingos - Niterói - RJ - Brasil - CEP: 24210-240. Endereços eletrônicos: lucianealcoforado@gmail.com; orlandolongo@gmail.com

\author{
Introdução \\ Área de estudo \\ Materiais e métodos \\ Resultados e discussão \\ Conclusões \\ Referências
}

\begin{abstract}
RESUMO - Uma das preocupações, quando se trata de leito fluvial, em regiões de bacias sedimentares, como o Estado do Acre é em relação ao comportamento que o leito fluvial apresenta, principalmente com a sua profundidade. Baseado nas medições realizadas, de 1971 até 2013, se verifica um comportamento no qual até o ano de 1985 a cota mínima do Rio Acre apresentava uma tendência crescente e a partir de 1986 esta cota apresenta uma tendência de redução, devido ao assoreamento que o rio vem sofrendo ao longo desses anos, considerando-se o aumento de volume de sedimentos transportados pelo rio. Como o Rio Acre, além de ser fonte de matéria prima para a construção civil, no caso a areia utilizada como agregado miúdo do concreto, bem como para o abastecimento de água, responsável por $100 \%$ da água fornecida à população do município de Rio Branco, a preocupação com o comportamento deste rio é constante. Desta forma, procurou-se, baseado nas medições e análises estatísticas, determinar o comportamento da evolução da cota mínima e do assoreamento do rio e através de previsões e projeções determinar o tempo que levará o rio para um assoreamento total, quando registrará uma cota de "zero" metro, impedindo a obtenção de areia e água para a demanda da população.

Palavras-chave: Assoreamento; Extração de Areia, Cota Mínima.
\end{abstract}

\begin{abstract}
One of the concerns when it comes to riverbed, in areas of sedimentary basins, such as the case of Acre is related to the behavior that the riverbed has, especially with its depth. Based on measurements conducted from 1971 until 2013, has been a behavior in which by the year 1985 the minimum quota of Acre River showed an increasing trend and from 1986 this share has shown a clear trend of reduction, a fact due to silting the river has suffered over the years, considering the increase in volume of sediment transported by the river. As the River Acre, besides being a source of raw materials for the construction industry, where the sand used as fine aggregate in concrete as well as for the supply of water, this river is responsible for $100 \%$ of the water supplied to the population Rio Branco, concern about the behavior of this river is constant. Thus an attempt was based on measurements and statistical analysis to try to determine the behavior of the evolution of the minimum quotas and silting of the river, and through predictions and projections determine the time it takes to display a total river siltation, as record a share of " zero " underground, thus preventing getting sand and water to meet the demand of the population.
\end{abstract}

Keywords: Sedimentation; Extraction of Sand; Minimum Quota.

\section{INTRODUÇÃO}

Os fatores naturais do processo erosivo podem estar relacionados ao clima, ação erosiva da água no terreno e cobertura vegetal, e além destes, encontram-se também os fatores antrópicos, como desmatamento, exploração mineral e expansão urbana. Destes fatores, no caso do Rio Acre, todos eles contribuem em uma maior ou menor escala para que possa ocorrer uma aceleração dos processos erosivos e consequentemente o assoreamento dos rios (Accorsi, 2001).

A extração mineral, também tem uma forte influência na engenharia, quando a partir dela se obtém matérias primas importantes para a construção civil. Segundo a classificação proposta por Oliveira \& Mauro (1993), os portos de areia são classificados em: Portos Ativos Operantes, Portos Ativos Inoperantes e Portos Desativados e, de acordo, com esta proposta de classificação, em Rio Branco, ocorrem os Portos Ativos Operantes, que estão em operação, recebendo e armazenando produto extraído dos leitos fluviais.

Para a exploração de areia, de uso imediato na construção civil, várias são as técnicas de exploração utilizadas, tais como: extração manual, em fossa, em área de várzea, em leitos de cursos d'água e em leitos de cursos d'água 
navegáveis dependendo de onde este material é encontrado.

No Estado do Acre, de modo geral, e, no caso do município de Rio Branco, de modo específico, por não existirem depósitos residuais, a areia utilizada na construção civil, sempre foi retirada diretamente dos leitos fluviais, sendo utilizada sem nenhum tratamento, tais como, seleção granulométrica adequada, retirada de material pulverulento e retirada de matéria orgânica, materiais estes que podem interferir na qualidade das obras executadas com este material arenoso.

Para a Engenharia Civil, a areia é bem mineral indispensável, e quanto melhor a qualidade da areia, melhor será o resultado final do produto. A partir de observações locais e análise da dinâmica fluvial, do comportamento do transporte e da sedimentação fluvial, os quais produzem os depósitos fluviais, procurou-se encontrar uma melhor localização para obtenção de um material arenoso que atenda às características geotécnicas e as normas técnicas para a sua utilização como agregado miúdo do concreto, bem como na confecção da argamassa para revestimentos.

No Acre o material utilizado como agregado miúdo é obtido nos leitos fluviais pelo processo de dragagem, processo que, além de fornecer material, pode se tornar um fator contribuinte no desassoreamento do rio Acre.

Oliveira \& Mello (2007) destacam que a extração de materiais aluvionares em rios vem sendo fortemente condenada por diversos setores da sociedade em função dos desequilíbrios que esta atividade pode causar na dinâmica fluvial. Os leitos ativos de rios são dinâmicos e respondem rapidamente aos estímulos externos, incluindo a extração de areia.
De acordo com Langer \& Glanzman (1993); Kondolf (1994); Owrri (1995), segundo Oliveira \& Mello (2007), em que pese todos os severos impactos que as ações antrópicas podem impor à dinâmica fluvial e aos ecossistemas aquáticos, mesmo assim, ainda é possível a extração de areia a partir de fontes localizadas em leito ativo de rios, sem criar impactos ambientais negativos, desde que sejam obedecidas as condições naturais de regime hidráulico do sistema fluvial, e mantidas as práticas apropriadas de exploração, garantindo, dessa forma, a sustentabilidade.

Dentre os conceitos e enfoques do termo sustentabilidade, Encarnação (2007) considera que a "sustentabilidade fomenta uma visão de desenvolvimento que suplanta o reducionismo, o desenvolvimento sustentável representa para o homem e para a natureza uma garantia de sobrevivência".

Ao longo, principalmente, das últimas três décadas, início de 1980 até 2013, constata-se que o Rio Acre apresenta uma clara diminuição da sua cota, pois quando se observa os valores da pluviosidade registrados em Rio Branco, não se verifica diferenças significativas de 1970 a 2013, sempre com valores anuais acima de $1500 \mathrm{~mm}$. Sendo assim, era de se esperar que as cotas do rio também não apresentassem uma diferença ao longo destes anos.

A partir de 1998, o Rio Acre apresenta uma linha de tendência sempre com valores inferiores a 2,5 metros, o que pode evidenciar assoreamento do rio, fator este que pode levar a um incentivo maior à dragagem de areia, que além de fornecer material para construção civil, auxilia no retorno do rio ao seu leito original e, assim, contribuir para a redução das inundações (Figura 1).

\section{ÁREA DE ESTUDO}

A área delimitada para estudo está localizada dentro da área urbana de Rio Branco, próximo ao Mercado Elias Mansour, no bairro Cadeia
Velha, onde estão instaladas as réguas limnimétricas para a medição da cota do rio (Figura 2).

\section{MATERIAIS E MÉTODOS}

Com os dados da Coordenação de Defesa Civil do Estado do Acre, sobre as cotas do Rio Acre, tanto as máximas quanto as mínimas, obtidos de leituras diárias, nas réguas limnimétricas instaladas na margem direita do Rio Acre no bairro Seis de Agosto, município de Rio Branco, os quais apresentam uma Série Histórica, contendo informações a partir de janeiro de 1971 até dezembro de 2013, com a qual foram executadas várias comparações. Também se utilizou de uma Série Histórica de medidas de pluviosidade em Rio Branco, de 1971 até 2013, a qual foi a base para as correlações entre as cotas e a pluviosidade e as vazões do rio Acre. 


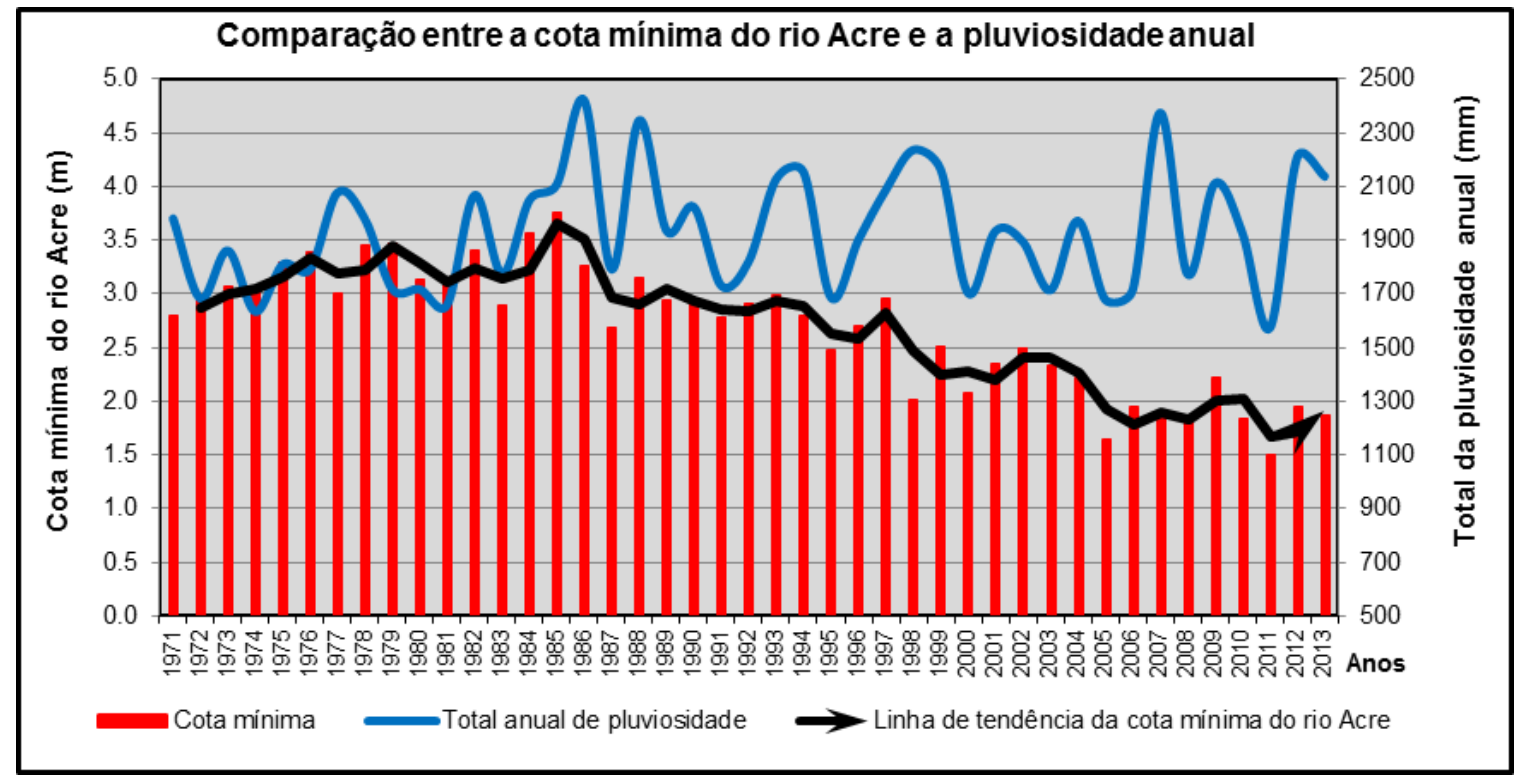

Figura 1- Comparação entre a cota mínima do rio Acre e a pluviosidade anual (1971-2013) (Fonte: Dados da Coordenadoria Estadual de Defesa Civil - CEDEC - Acre).

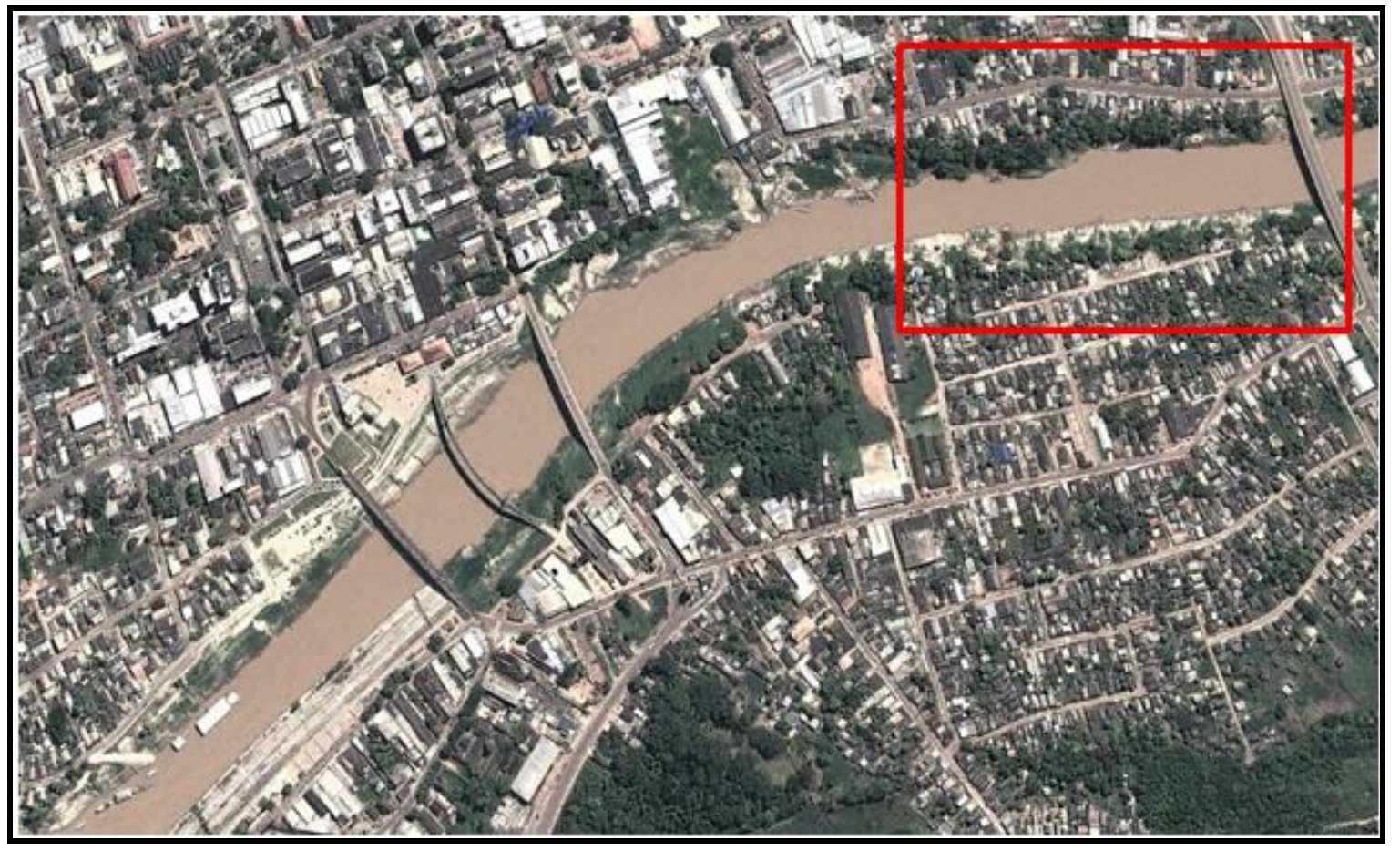

Figura 1 - Localização da área de estudo. Coordenadas: 9॰58’34”S a 958’28” S / 6748’03”O a 6747'52" O (Fonte: Google EarthTM Mapping Service, 2013)

Por meio de um corte transversal hipotético no rio Acre, e com o auxílio da ferramenta computacional, Software GeoGebra, conseguiu-se mostrar como se encontra o leito do rio atualmente e assim determinar duas zonas, que apresentavam duas faixas de assoreamento no Rio Acre, onde determinou-se a área correspondente ao material acumulado no fundo do rio, constatando-se o assoreamento do rio ao longo destes 43 anos (Figura 3).
A zona 1, que corresponde à diferença das médias das cotas mínimas do ano de 1971 a 1990 (limite inferior) e de 1991 a 2000 (limite superior), apresenta uma área correspondente a $26,80 \mathrm{~m}^{2}$. A zona 2, que corresponde a diferença das médias das cotas mínimas do ano de 1991 a 2000 (limite inferior) e de 2001 a 2013 (limite superior), apresenta uma área correspondente a $31,00 \mathrm{~m}^{2}$. O material assoreado no Rio Acre, ao longo desses 23 anos, corresponde a uma área de $57,80 \mathrm{~m}^{2}$. 


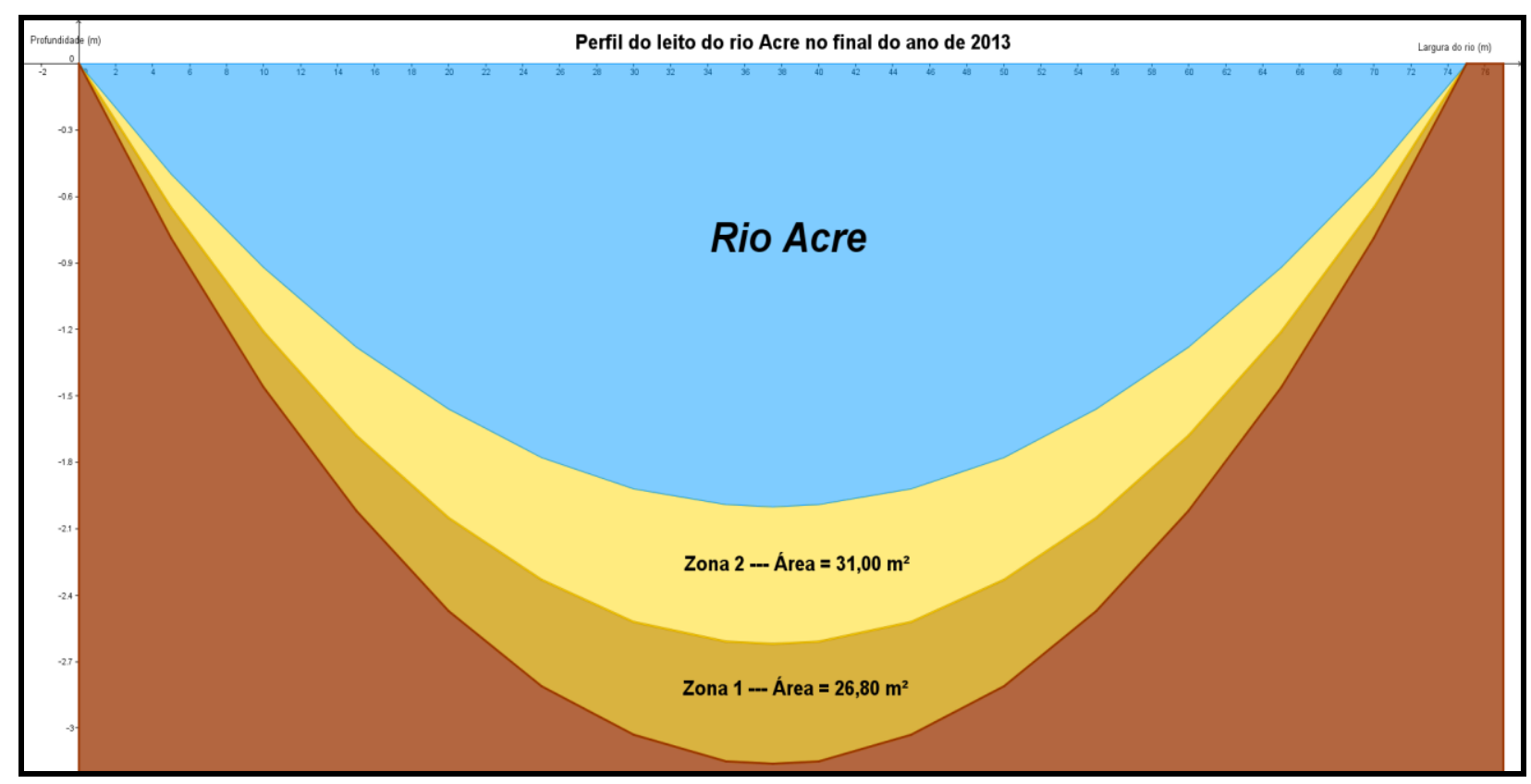

Figura 3 - Perfil batimétrico hipotético do rio Acre no final do ano de 2013, a partir das cotas mínimas.

A partir das análises estatísticas realizadas foi possível estabelecer uma previsão com relação ao comportamento das cotas do Rio Acre ao longo dos próximos 50 anos.

Como se percebe visualmente nos dados, ocorre uma tendência de um modelo linear de $1^{\circ}$ grau.

Neste sentido foi utilizado para a modelagem o seguinte modelo:

$$
y_{i}=\beta_{0}+\beta_{1} x_{i}+e_{i} \quad \text { (Eq. 1), }
$$

Onde:

$\boldsymbol{y}_{\boldsymbol{i}}$ é a cota máxima no ano $\boldsymbol{x}_{\boldsymbol{i}}$;

$\boldsymbol{x}_{i}$ é o $i$-ésimo ano;

$\boldsymbol{\beta}_{0}$ é o coeficiente linear da reta ou termo constante;

$\beta_{1}$ é o coeficiente angular da reta que indicará a taxa de variação; e

$\boldsymbol{e}_{\boldsymbol{i}}$ é o erro aleatório, supostamente normal com média zero e variância constante $\sigma^{2}$, ou seja, $\boldsymbol{e}_{i} \sim \mathrm{N}\left(0, \sigma^{2}\right)$.

Além disso, supõe-se que os $\boldsymbol{e}_{\boldsymbol{i}}$ 's são independentemente distribuídos.

Para a estimação dos parâmetros $\boldsymbol{\beta}_{\boldsymbol{0}}$ e $\boldsymbol{\beta}_{\boldsymbol{1}}$, considerando-se o Método dos Mínimos Quadrados, foram usadas as seguintes relações, conforme (Draper \& Smith, 1998, segundo Morettin \& Bussab, 2010):

$$
\begin{aligned}
& \widehat{\boldsymbol{\beta}}_{0}=\overline{\boldsymbol{y}}-\widehat{\boldsymbol{\beta}}_{1} \overline{\boldsymbol{x}} \\
& \widehat{\boldsymbol{\beta}}_{1}=\frac{\sum_{i=1}^{n} x_{i} y_{i}-n \overline{x y}}{\sum_{i=1}^{n} x_{i}^{2}-n \bar{x}^{2}}
\end{aligned}
$$

Os intervalos de confiança ao nível de 95 $\%$ para os parâmetros $\boldsymbol{\beta}_{\boldsymbol{0}}$ e $\boldsymbol{\beta}_{\boldsymbol{1}}$ foram encontrados conforme Draper \& Smith, (1998, segundo Bussab \& Morettin, 2010):

$$
\mathrm{IC}\left({ }^{\beta_{i} ; \gamma}\right) 95 \%=\hat{\beta}_{\mathrm{i} \pm} t_{\gamma,(n-2)} S_{e} \sqrt{\frac{\sum_{i=1}^{n} x_{i}^{n}}{n \sum_{i=1}^{n}\left(x_{i}-\bar{x}\right)^{2}}}
$$

Além disso, para cada parâmetro foi realizado um teste $t$ de Student ao nível de significância de $5 \%$, conforme as seguintes hipóteses:

$$
H_{0}: \beta_{i}=0 \quad / \quad H_{1}: \beta_{i} \neq 0
$$

Um Teste $F$ (ANOVA) também foi realizado para verificar se o modelo de $1^{\circ}$ grau como um todo era pertinente. Neste caso, a seguinte hipótese foi considerada:

$$
\begin{aligned}
& H_{0}: \beta_{0}=\beta_{1}=0 ; \\
& H_{1}: \text { pelo menos em }{ }^{\beta_{i}} \neq 0 .
\end{aligned}
$$

Para cada resposta estimada foram encontrados os Intervalos de Confiança para $\mu(x)=\beta_{0}+\beta_{1} x_{i}$ dados por:

$$
\boldsymbol{I C}(\boldsymbol{\mu}(\boldsymbol{x}) ; \gamma)=\bar{y}_{i} \pm \boldsymbol{t}_{\gamma /(n-2)} s_{e} \sqrt{\frac{1}{n}+\frac{\left(x_{i}-\bar{x}\right)^{2}}{\sum_{i=1}^{n}\left(x_{i}-\bar{x}\right)^{2}}}
$$

Isto também foi realizado com os Intervalos de Predições, conforme:

$$
I P\left(y_{f} ; \gamma\right)=\bar{y}_{f} \pm t_{\gamma,(n-2)} s_{e} \sqrt{1+\frac{1}{n}+\frac{\left(x_{i}-\bar{x}\right)^{2}}{\sum_{i=1}^{n}\left(x_{i}-\bar{x}\right)^{2}}}
$$

(Eq. 6) 
onde $\boldsymbol{y} \boldsymbol{f}$ é a observação futura, $\boldsymbol{S}_{\boldsymbol{e}}$ é o desvio padrão do resíduo e $\boldsymbol{t}_{\boldsymbol{\gamma}},(\boldsymbol{n}$-2) é um quantil da distribuição $t$ de Student com " $n-2$ " graus liberdade.

Para verificar se o que foi pressuposto sobre os erros $\boldsymbol{e}_{\boldsymbol{i}}$ não está sendo violado, foram feitas análises visuais de gráficos dos resíduos, conforme Draper \& Smith (1998, segundo Morettin \& Bussab, 2010):

1. Gráfico quantil $x$ ordem das amostras, para verificar a normalidade;

2. Gráfico dos quantis teóricos $x$ quantis dos resíduos padronizados;

3. Gráfico dos Resíduos padronizados $x$ amostras, para verificar hipóteses de independência e homocedasticidade das variâncias; e

4. Gráfico dos Resíduos $x$ amostras, para verificar as hipóteses de independência e homocedasticidade das variâncias.

\section{RESULTADOS E DISCUSSÃO}

Para as análises foram utilizados os Softwares R (versão 3.0.2 para Windows) e o Microsoft Excel (2010).

Ao tratar-se especificamente das cotas do Rio Acre, considerando-se as leituras executadas pela Defesa Civil, nos 43 anos (1971-2013), tem-se a observar que:

- A maior cota máxima medida no Rio Acre foi de 17,66 metros, no ano de 1997 e a menor cota máxima foi de 11,37 metros no ano de 1980;

- A cota mínima variou de 3,76 metros, no ano de 1985, até a menor cota mínima registrada, que foi de 1,50 metros, no ano de 2011, apesar de que, em alguns anos estes valores apresentaram variações para maior ou para menor, se constata claramente uma crescente diminuição da cota, caracterizando assim o assoreamento que o rio vem sofrendo ao longo destes 43 anos, período desde quando a Defesa Civil vem realizando estas medidas; e

- A partir dos dados levantados, a cota mínima apresenta uma variação de 2,26 metros $(3,76 \mathrm{~m}-1,50 \mathrm{~m})$, demonstrando assim uma tendência crescente da diminuição da cota.

Analisando o comportamento da cota mínima do rio, ao longo desses 43 anos de medições, constatou-se claramente que, de 1971 até 1985, as cotas mínimas apresentavam uma linha de tendência crescente e a partir daí uma tendência muito marcante decrescente (Figura 4).

A partir da média das cotas mínimas do período de 1991-2000, que é de 2,62 metros foi construído o perfil hipotético do fundo do rio Acre. Esta cota foi considerada como de maior profundidade, neste período, para a finalidade de se observar as duas zonas de assoreamento, já apresentadas na Figura 3.

Experimentalmente, para a determinação do volume do assoreamento que o rio Acre está sofrendo, o que se constata pela variação da profundidade do rio, ao longo destes 43 anos, foi considerada uma seção longitudinal, de 50 metros a montante e 50 metros a jusante do local onde foram realizadas as medições (Figura 5).

Portanto, os valores considerados para cálculo do volume do material arenoso depositado, serão os dados relativos às áreas da zona 1 e da zona 2, por uma seção longitudinal de 100 metros para estipularmos o volume de material depositado.

Ao longo de 23 anos ocorreu uma diminuição da cota do rio Acre, de 1,16 metros, o que corresponde a uma área de $57,80 \mathrm{~m}^{2}\left(26,80 \mathrm{~m}^{2}+31,00 \mathrm{~m}^{2}\right)$; considerando uma largura média do rio de 75 metros. Quando se define o volume, considera-se uma seção longitudinal de 100 metros, apresentando um volume de material assoreado de $5.780 \mathrm{~m}^{3}\left(57,80 \mathrm{~m}^{2} \times 100 \mathrm{~m}\right)$. Baseado nestes valores verifica-se que, em 23 anos (1991-2013) ocorreu um assoreamento de 1,16 metros (3,16 m-2,00 $\mathrm{m})$. Como a menor cota do Rio Acre verificada em 2011, de 1,50 m, conclui-se que, se as condições atuais forem mantidas, em termos de ocupação das margens do rio e destruição da mata ciliar e, se nada for feito para se evitarem as ocupações e os processos erosivos, em um período de aproximadamente 30 anos o leito do rio ficará totalmente assoreado.

Considerando este valor como constante, observa-se que, se em 23 anos o rio apresentou um assoreamento de 1,16 metros, então em um ano verifica-se uma taxa de 


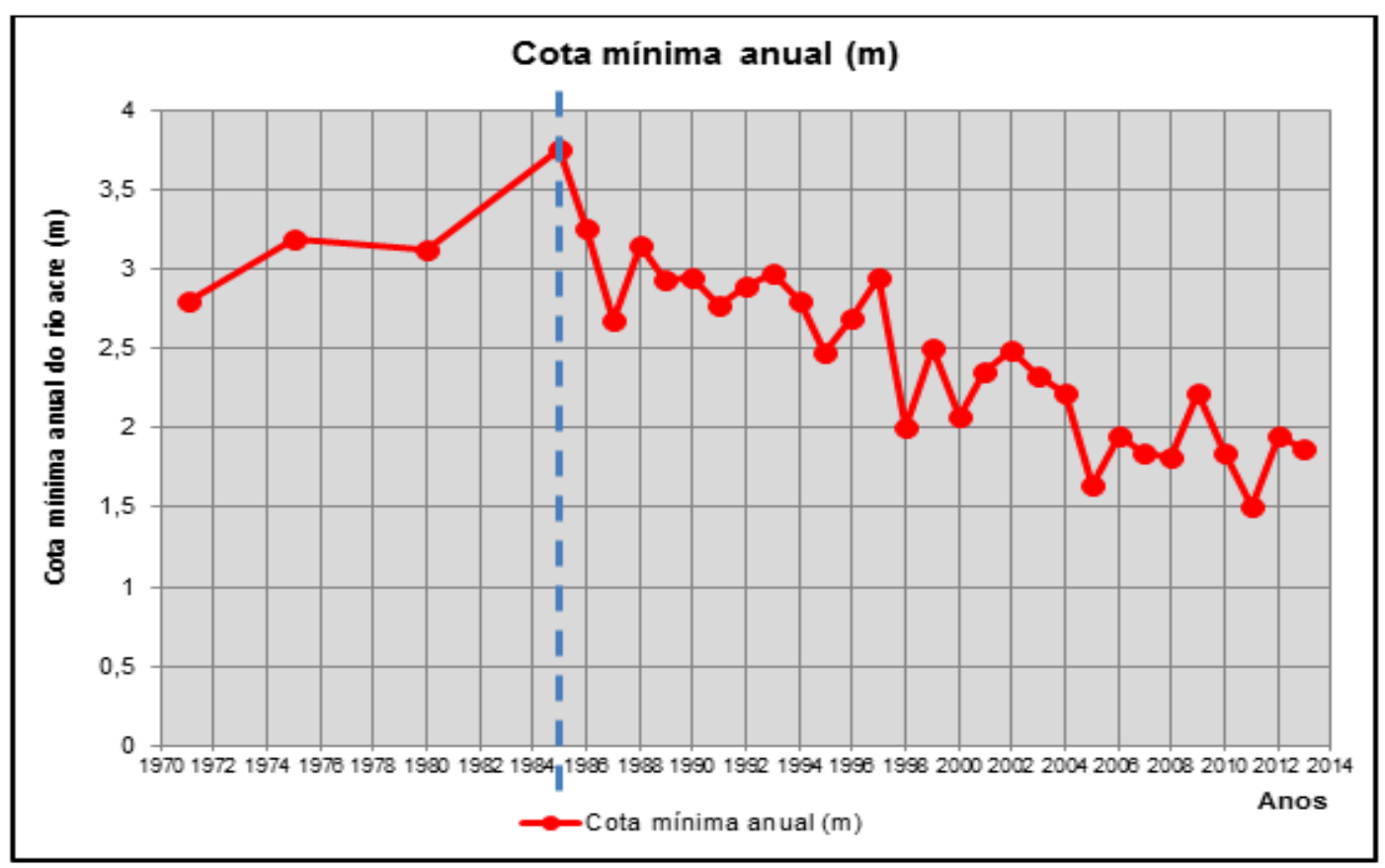

Figura 4 - Comportamento da cota mínima anual no rio Acre de 1971 a 2013. (Fonte: Dados da Coordenadoria Estadual de Defesa Civil - CEDEC - Acre)

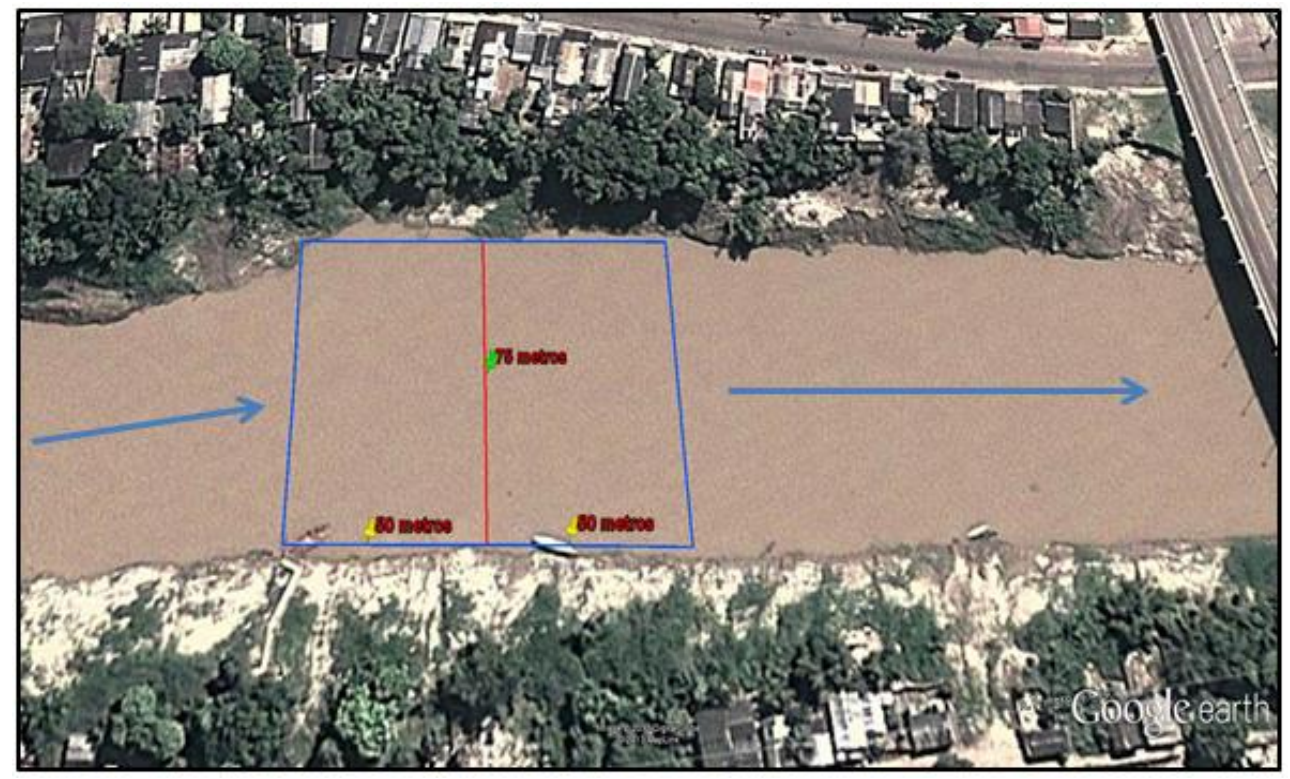

Figura 5 - Seção longitudinal do rio Acre para o cálculo do volume de material assoreado no leito do rio. (Fonte: Google Earth ${ }^{\mathrm{TM}}$ Mapping Service (2013) - Adaptado

0,050 metros/ano. Nesta taxa de assoreamento, nos próximos 30 anos, a tendência é que o rio, no local das medições, apresentese seco, ou seja, totalmente assoreado nesse momento, com uma cota de zero metro e um assoreamento de 1,50 metros (30 anos $\mathrm{x}$ $0,050 \mathrm{~m} /$ ano $=1,50$ metros $)$.

O objetivo é determinar, quando o rio irá atingir a cota "zero" metro, considerando as condições hidrológicas, geológicas, populacionais, erosivas, entre outras, que se apresentaram até hoje. Sendo assim, analiticamente constata-se que o rio apresentará o "zero" metro no ano de 2043.
Foram realizadas previsões futuras sobre o comportamento da cota mínima do Rio Acre para os próximos anos, estimando a tendência de a cota mínima apresentar um valor de "zero" metro.

Baseado na análise da regressão linear e considerando os limites superiores e inferiores de confiança, bem como, os limites superiores e inferiores de predição, nesta análise de regressão e nas previsões realizadas, foi possível à confecção do gráfico com os respectivos limites (Figura 6), que subsidiaram as conclusões desta pesquisa. 


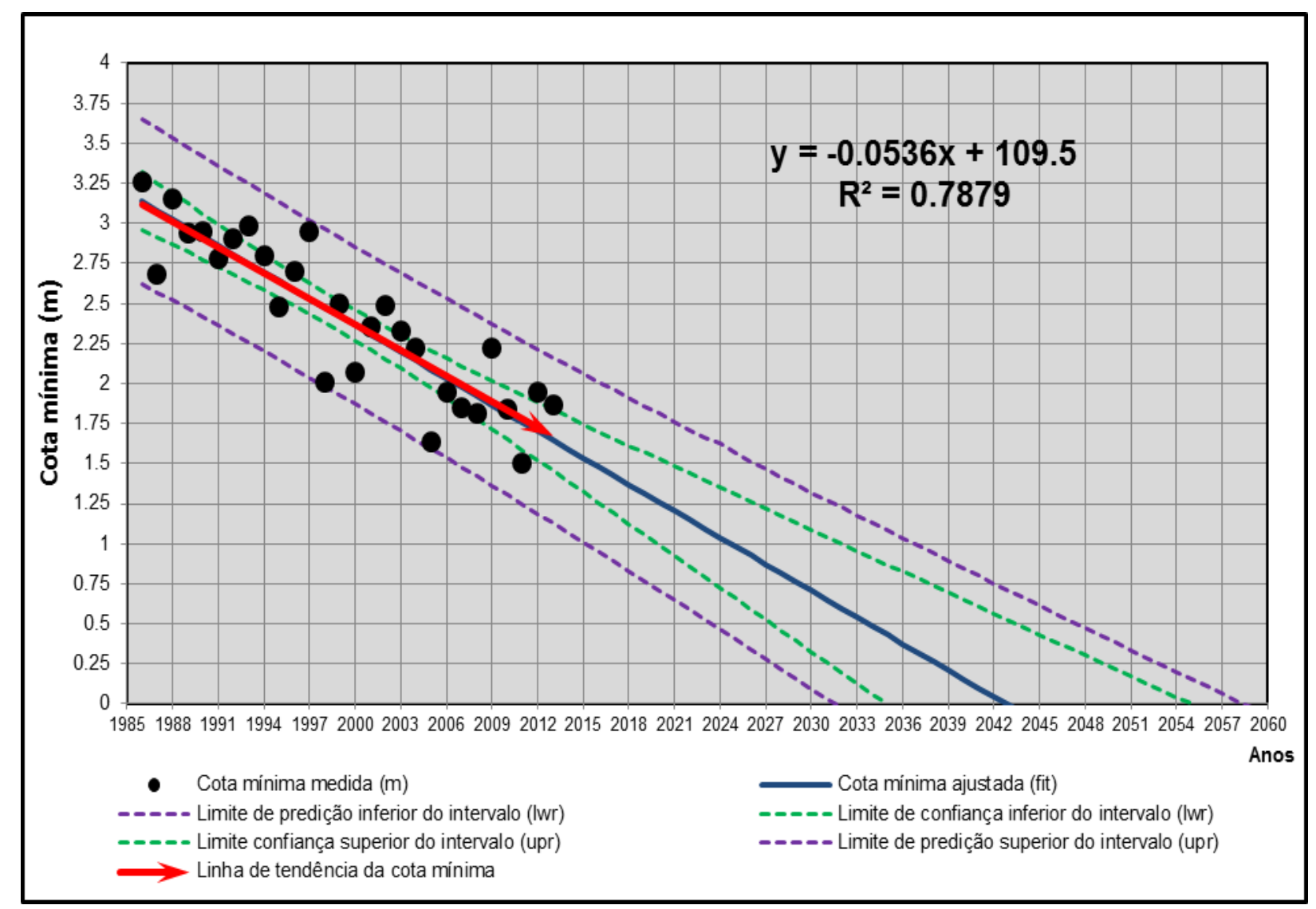

Figura 6 - Ajuste do modelo de regressão linear simples para a variável cota mínima em função dos anos. As linhas tracejadas representam os intervalos de Predição e os Intervalos de Confiança para os valores médios.

As análises estatísticas realizadas, com a utilização dos Softwares R (versão 3.0.2 para Windows) e o Microsoft Excel (2010), foi possível serem feitas previsões com relação ao comportamento das cotas do Rio Acre, até aproximadamente o ano de 2060, considerando os limites superiores de predição e de confiança.

A previsão para o ano em que o Rio Acre atinja a cota de "zero" metro, considerando as condições atuais, é o ano de 2043. Nas análises mais pessimistas, considerando-se os limites mínimos de predição e confiança, o Rio Acre terá a cota "zero" metro nos anos de 2032 e 2035, respectivamente; e nas análises mais otimistas, considerando-se os limites máximos de confiança e predição, o Rio Acre terá a cota "zero" metro nos anos de 2055 e 2058, respectivamente.
A equação estimada:

$$
y_{i}=109,50-0,0536 x_{i} \quad \text { (Eq. 7) }
$$

A partir da equação (Eq. 7), verificou-se que a taxa de variação anual na Cota Mínima é de menos $0,0536 \mathrm{~m}$ ao ano, ou seja, a cada ano a cota mínima tende a diminuir 0,0536 metros, com intervalo de confiança de $95 \%$, igual a $[-0,0648 ;-0,0424]$, conforme Tabela 1 .

Assim, o ano estimado pela equação para que o rio atinja a cota "zero" metro será em 2043. Na tabela a seguir estão os valores estimados para os parâmetros $\boldsymbol{\beta}_{\boldsymbol{0}}$ e $\boldsymbol{\beta}_{\boldsymbol{1}}$ da reta de regressão e os resultados do teste $\boldsymbol{t}$ de Student, para as hipóteses de nulidade de tais parâmetros: (Tabela 1).

Análise de Variância para o modelo de regressão (Tabela 2).

Tabela 1 - Testes de hipóteses para a significância dos parâmetros do modelo e Intervalos de Confiança (IC) a $95 \%$ para os mesmos.

\begin{tabular}{|c|c|c|c|c|c|}
\hline \multirow{2}{*}{ Parâmetro } & \multicolumn{2}{|c|}{ IC $(95 \%)$} & \multirow{2}{*}{ Estimativa } & \multirow{2}{*}{ Erro padrão } & \multirow{2}{*}{$P$ - valor } \\
\hline & $95 \%$ inferiores & $95 \%$ superiores & & & \\
\hline$\beta_{0}$ & 87,10335 & 131,904762 & 109,5041 & 10,89778 & $<0,0001^{*}$ \\
\hline$\beta_{1}$ & $-0,06477$ & 0,0423629 & $-0,05357$ & 0,00545 & $<0,0001^{*}$ \\
\hline
\end{tabular}

* indica que a hipótese nula é rejeitada ao nível de significância de $5 \%$. 
Tabela 2 - Análise de variância e teste $\boldsymbol{F}$ para o modelo de regressão.

\begin{tabular}{c|c|c|c|c}
\hline FV & GL & SQ & QM & F \\
\hline Modelo & 1 & 4,9957 & 4,9957 & $91,334^{*}$ \\
\hline Resíduos & 25 & 1,3674 & 0,0547 & - \\
\hline Total & 26 & 6,3631 & - & - \\
\hline * indica que a hipótese nula é rejeitada ao nível de significância de 5\%. \\
FV: Fonte de Variação; GL: Grau de Liberdade; SQ: Soma de Quadrados; QM: Quadrado Médio
\end{tabular}

Todos os gráficos da Análise de Resíduos indicaram que, as pressuposições feitas sobre o modelo não foram violadas, indicando que o modelo é plausível para os dados.

Portanto, a previsão para que o Rio Acre atinja a cota "zero" metro, bem como os limites de confiança e os limites de predição, obtidos a partir da Regressão Linear são adequados.

Quando realizamos as diversas comparações, para a obtenção de uma possível previsão para que o Rio Acre atinja a cota "zero" metro, vários cenários, alguns mais pessimistas e outros mais otimistas, baseados nos intervalos de confiança e predição são apresentados na Tabela 3.

Tabela 3 - Previsões para que o Rio Acre atinja a cota "zero" metro.

\begin{tabular}{c|c}
\hline \multicolumn{1}{c|}{ Previsões } & Ano que o rio vai atingir a cota "zero" metro \\
\hline $\begin{array}{c}\text { Considerando a Regressão Linear da cota mínima anual } \\
\text { de 1986-2013 }\end{array}$ & 2043 \\
\hline Considerando os limites mínimos e máximos de confiança. & 2035 a 2055 \\
\hline Considerando os limites mínimos e máximos de predição. & 2032 a 2058 \\
\hline
\end{tabular}

A partir de todas as análises e previsões realizadas é que na hipótese mais otimista, o rio Acre vai se apresentar totalmente assoreado, portanto, com a cota de "zero" metro, no local onde o estudo foi realizado, no ano de 2058, portanto daqui a 44 anos. Quando consideramos uma hipótese mais pessimista, considerado o cenário mais preocupante, em 2032, o Rio Acre já estará assoreado totalmente, no local estudado.

Neste sentido, se propõe que para o rio não secar, deve-se estimular a dragagem de maneira adequada, pois assim, além de se retardar o assoreamento, pode-se conseguir com que o rio aumente a profundidade de seu leito, ao mesmo tempo em que possibilitaria a obtenção de material arenoso para a construção civil e a prevenção das inundações, que cada vez mais atingem o município de Rio Branco, pois o leito está ficando cada vez menos profundo.

Nesta pesquisa não se discute as causas que possibilitam, ou aceleram o assoreamento, apenas levantamos algumas considerações sobre as possíveis causas.

$\mathrm{O}$ processo de dragagem, se estimulada, dentro de um controle ambiental nos locais onde os processos de assoreamento estão mais evidentes, com a retirada de areia a partir das dragas de sucção, as quais apresentam uma produção nominal de 20 $\mathrm{m}^{3} /$ hora a $6 \mathrm{~m}^{3} /$ hora, poderá ser controlada a taxa de assoreamento, prevenindo a seca do rio e ao mesmo tempo proporcionando a produção de material para a construção civil.

Normalmente, no município de Rio Branco, a retirada de areia do rio é executada a partir de um Motor bomba acoplado a uma bomba de sucção com diâmetro de $6 \times 6$ " ou $4 \times 4$ ", instalado em uma balsa, que através de tubos de PVC de $150 \mathrm{~mm}$ de diâmetro enviam a polpa (areia+silte+argila+água) para os poços de decantação, apresentando os seguintes valores de produção nominal. A bomba de sucção de 6x6" apresenta uma produção nominal mensal de $3.200 \mathrm{~m}^{3} / \mathrm{mês}$ e a bomba de $4 \times 4$ ", uma produção nominal mensal de $960 \mathrm{~m}^{3} /$ mês. Estas produções nominais são aquelas realizadas em condições ideais, sendo que em condições de trabalho sempre ocorre uma redução nestes valores. 
É importante ressaltar que o material arenoso utilizado na construção civil tem como única fonte de obtenção o leito fluvial, portanto esta atividade não pode ser simplesmente extinta da atividade produtiva do Acre, com o risco de causar um colapso na construção civil.

Considerando os valores do material depositado, no local que foi estudado, que corresponde a $5780 \mathrm{~m}^{3}$ nestes 23 anos de deposição, o período para recuperação do leito do rio seria de:

- A partir de uma bomba de sucção de 6x6" e considerando a produção nominal diária (160 $\mathrm{m}^{3} /$ dia) levaríamos aproximadamente 36 dias $\left(5.780 \mathrm{~m}^{3} \div 160 \mathrm{~m}^{3} /\right.$ dia) de trabalho ininterrupto para recuperarmos o leito do rio nesse local; e

- A partir de uma bomba de sucção de 4x4" e considerando a produção nominal diária (48 $\mathrm{m}^{3} /$ dia) levaríamos aproximadamente 102 dias $\left(5.780 \mathrm{~m}^{3} \div 48 \mathrm{~m}^{3} /\right.$ dia) de trabalho ininterrupto para recuperarmos o leito do rio nesse local.

Tem-se que considerar que esta taxa de retirada corresponde a uma condição ideal, porém deve-se levar em conta também que, mesmo durante o período de retirada, o rio continua a depositar material. Estes valores encontrados consideram como se neste período não ocorresse mais nenhuma deposição, o que não é verdadeiro, pois o rio continua com sua atividade hidrodinâmica, erodindo e depositando material.

\section{CONCLUSÕES}

A extração de areia em leitos fluviais, quando com orientação técnica correta, pode ser benéfica para a manutenção do leito fluvial, prevenindo e reduzindo o assoreamento do rio e ao mesmo tempo atendendo a demanda socioeconômica pelo recurso explorado, com a utilização imediata na construção civil, uma vez que é a única fonte abastecedora de areia no município de Rio Branco.

Como resultados do desenvolvimento da pesquisa para a caracterização da bacia hidrográfica do Rio Acre foi possível se chegar a algumas conclusões importantes:

- Como está ocorrendo um assoreamento acelerado justifica-se então, como mecanismo para o controle de inundações e para a própria obtenção de materiais arenosos para a utilização na construção civil, a dragagem do leito do rio para que ele retorne ao seu leito original;

- Também a bacia do Rio Acre apresenta características de rios que correm em regiões de relevo plano, apresentando uma carga de material transportado muito grande, principalmente de granulometria muito fina (areia fina, silte e argila), sendo transportado em suspensão mecânica o que fica evidenciado pela coloração e o aspecto barrento da água e apresentando muitos meandros, também uma característica de rios que se desenvolvem em regiões de materiais sedimentares, onde $\mathrm{o}$ processo erosivo é muito intenso, independente da ação antrópica que possa vir a ocorrer;

- Nos locais de dragagem de areia, na área de estudo se constatou que, quanto mais próximo do talude era a instalação das dragas para a extração de areia, mais evidentes eram os processos erosivos e de movimentos de massa que ocorriam;

- Foi constatado a partir de medições um assoreamento do rio Acre a partir do ano de 1985, o que está levando a diminuição da cota do rio Acre ao longo dos anos, desde 1985 até 2013;

- A partir de todas as análises estatísticas e previsões realizadas é que na hipótese mais otimista, o Rio Acre vai se apresentar totalmente assoreado, portanto, com a cota de "zero" metro, no local onde o estudo foi realizado, no ano de 2058, portanto daqui a 44 anos. Quando em uma hipótese mais pessimista, considerado o cenário mais preocupante, em 2032 o Rio Acre já estará assoreado totalmente, no local estudado; e

- Com a estimulação da dragagem, em locais específicos, onde os processos de assoreamento são mais acentuados, esses efeitos da diminuição da cota do Rio Acre podem ser revertidos.

Desta forma, deve-se propor uma adequação da legislação às condições e peculiaridades locais, para que se possa exigir o cumprimento das normas e proceder a uma fiscalização de forma efetiva. A partir desse procedimento, incentivar para que os mineradores de areia sejam licenciados, reduzindo ou mesmo evitando os possíveis impactos ambientais negativos originados a partir deste tipo de explotação mineral. 


\section{REFERÊNCIAS}

ACCORSI, O.J. Mineração de areia no Rio Acre e os problemas ambientais associados: Trecho da área urbana de Rio Branco - AC. Rio Claro, 2001, 137 p. Dissertação (Mestrado em Geociências e Meio Ambiente) - Instituto de Geociências e Ciências Exatas, Universidade Estadual Paulista.

ACRE. Governo do Estado do Acre. Coordenadoria Estadual de Defesa Civil. Corpo de Bombeiros Militar. 2012.

ENCARNAÇÃO, F.L. Da educação ambiental e sua imersão no ambiente escolar: um diálogo horizontal entre sujeitos e seus saberes. Rio Grande do Sul, 2007. Dissertação (Mestrado). Fundação Universidade Federal do Rio Grande. GOOGLE EARTH ${ }^{\mathrm{TM}}$ MAPPING SERVICE (2013). Image $\odot 2012$ Digital Globe. Consulta realizada em Julho/2013.

MORETTIN, P.A. \& BUSSAB, W.O. Estatística básica. $6^{\text {a }}$ ed. São Paulo: Saraiva, 540, p. 2010 Software GeoGebra. International GeoGebra Institute. http://www.geogebra.org/.
OLIVEIRA, C.M. \& MAURO, C.A. DE. Exploração de areia e cascalho no Rio Mogi-Guaçu/Araras, SP. In: SIMPÓSIO NACIONAL DEGEOGRAFIA FÍSICA APLICADA, 1993, São Paulo. Anais... São Paulo: Associação de Geógrafos Brasileiros, 1993, p. 65-76.

OLIVEIRA, F.L. \& MELLO, E.F. A mineração de areia e os impactos ambientais na bacia do rio São João, RJ. In: Revista Brasileira de Geociências, v. 37, n. 2, p. 374-389, 2007.

Manuscrito recebido em 30 de novembro de 2015 Revisado e aceito em 7 de novembro de 2016 